\title{
Nutrition students and mathematics: Competent but not confident
}

\author{
K. Clark ${ }^{1}$, A. Cooke ${ }^{2}$, A. James ${ }^{1}$, R. Halse ${ }^{1}$
}

\begin{abstract}
Aim: To assess skills, competence and disposition of nutrition students towards mathematics.

Methods: A cross-sectional study was conducted at Curtin University, Perth, Western Australia, to assess the numeracy of undergraduate nutrition students enrolled in a level 2 biochemistry unit $(n=40)$. Primary outcome measures were evaluations of competence when answering discipline-specific questions and students' confidence and perceived ease and disposition towards mathematics.

Results: The majority of students were competent (mean diagnostic test score $=72 \%$ ), with only four students scoring below the competence midpoint. However, many students reported low confidence and a high perception of difficulty, indicated by the majority of scores above the line of equality in self-confidence and ease of questions. Furthermore, $30 \%$ of students identified as having anxiety related to mathematical understanding and mathematical knowledge below the midpoint.
\end{abstract}

Conclusions: Results showed a significant proportion of students were not confident with mathematics, despite being competent. Anxiety concerning knowledge and understanding was present in 30\% of students. These findings are important for tailoring a numeracy support framework that specifically addresses confidence and disposition towards mathematics to ensure that students can succeed in the mathematical challenges inherent to their course and future nutrition career.

Keywords: mathematics; nutrition; competence; confidence; disposition; anxiety

School of Public Health, Curtin University, Bentley, Western Australia, Australia

School of Education, Curtin University, Bentley, Western Australia, Australia

\section{Correspondence}

Karin Clark

School of Public Health

Curtin University

GPO Box U1987

Perth, WA 6845

Australia

Tel: +61 892662538

Email: karin.clark@curtin.edu.au 


\section{Introduction}

Numeracy is an essential element of tertiary study, required in order for students to successfully engage with and complete their course (Donaldson et al., 2010; Johnson \& O'Keeffe, 2016; McNaught \& Hoyne, 2013) and meet course learning outcomes (Brady, 2014). In contextual terms similar to Galligan (2011, 2013), student nutritionists and dietitians must be able to evaluate and problem solve as part of their studies and future profession. Management of multi-step calculations of energy and nutrient intakes is required in consultation with people about food and serving sizes and to conceptualise nutrient reference values. Students must be able to undertake laboratory calculations involving dilutions and molar concentrations, fractions, ratios and unit conversions and assess whether their answers are realistic. Moreover, students are expected to have confidence with statistical evaluation and interpretation of health data from research studies for dissemination as well as to interpret clinical test results. Nutritionists must identify mathematical ideas within a nutrition context and have the confidence and capability to apply mathematics. Additionally, quantitative and critical thinking skills are essential to everyday life (Kemp \& Hogan, 2000). Professional standards of the nutrition and dietetics disciplines are underpinned by numeracy; both professions are strengthened by use of critical thinking and evidence-based approaches (DAA, 2015; Lawlis et al., 2019; NSA, 2017). For students of nutrition and dietetics, difficulty in applying mathematical skills may hinder progress in their course and potentially result in higher attrition rates in the degree.

Anxiety and frustration over mathematics is a problem across health sciences courses; for example, entry-level nursing and midwifery students have been reported to have low confidence and competence in numeracy despite the inherent importance of dose calculations for drug administration in this discipline (Arkell \& Rutter, 2012). The impact of disposition towards mathematics has been well documented with preservice schoolteachers (Cooke, 2014; Isiksal et al., 2009). Students' past, current and future experiences with mathematics can affect their willingness to "have-a-go" (AAMT \& Education Department of Western Australia, 1997). For instance, numeracy experiences at high school may affect students' confidence to engage with the required level of mathematics at university (Galligan, 2011).

Anecdotally, nutrition students have reported mathematical content in their studies causes anxiety; however, to date, there is no published literature detailing these issues in nutrition student education. Mathematical anxiety may be associated with disengagement, preventing students from undertaking calculations essential to pass their units, irrespective of whether they have ability. For instance, it is noted that subsets of nutrition students in a core second-year biochemistry unit at Curtin University avoid calculation questions in tests and do not satisfactorily engage with laboratory calculations (James, 2015). Disengagement with mathematical content is evident with a typical fail rate of $20 \%$ in this unit. Similarly, across other Australian university nutrition courses, the most commonly failed units are those requiring students to apply mathematical concepts (A. Coates, A. Devine, T. Lawlis \& S. Torres, personal communication, 
November 28, 2015). Disengagement from mathematics can be so dramatic that it excludes students from their preferred courses of study and career choice (Brady, 2014).

Descriptions of numeracy incorporate not only the ability to solve mathematical problems but also having confidence and critical awareness (Galligan \& Hobohm, 2015). Similarly, Boreland (2016) describes numeracy as "quantitative literacy", referring to taking numerical skills and applying them to a broader context. "Academic numeracy" can be further defined as having confidence to use mathematics in a professional context, being able to step back and identify the mathematical ideas both evident within the context and held by the individual, and whether the individual was confident in their mathematical skills (Galligan, 2011, 2013). Avenues to measure and, importantly, address issues of mathematical competence, confidence and disposition are established at the School of Education, Curtin University (Cooke, 2014). Instruments have been designed and validated for use in the Bachelor of Education degrees and professional learning for in-service teachers to measure confidence, competence, attitudes and conceptualisation of mathematics.

Sufficient numeracy during tertiary education is not only a prerequisite for course completion but also for successful entry into students' associated chosen professions, in which numeracy requirements often "go beyond a command of [core] mathematical content" (AAMT \& AI Group, 2014, p. 32). Wilkins (2016) proposed that numeracy for tertiary students is so important that universities should include it as a graduate attribute, yet few Australian university policies even mention numeracy as they do literacy.

To date, there are no published data describing issues that contribute to mathematical ability in nutrition students, although mathematics is fundamental to many aspects of the discipline. This paper aimed to investigate the ability (i.e., competence) of undergraduate nutrition students at Curtin University, Perth, Western Australia, to answer discipline-appropriate calculation questions. We aimed to relate the mathematical competence of these students to how confident they were with their answers and their perception of the ease of each question. We also asked additional questions to measure overall anxiety, attitudes and conceptualisation of mathematics. These questions enabled the participating nutrition students to share their perceptions of their competence, anxiety, attitudes and conceptualisation of mathematics to situate this research within an interpretivism epistemology and constructionism ontology (Bryman, 2012).

\section{Methods}

This cross-sectional study involved an online numeracy diagnostic test. The diagnostic test was based on a validated instrument used in the School of Education, Curtin University and contextualised with discipline-specific mathematical calculations. Students were also asked questions relating to their disposition towards and willingness to engage in mathematics. The test was administered to undergraduate nutrition students in a core second-year biochemistry unit, where application of numeracy is 
inherent. The unit follows two first-year chemistry prerequisite units where numeracy is also fundamental.

A total of 100 students enrolled in the unit were invited to take part in the research study. Students were distributed across the undergraduate BSc courses of nutrition and food science $(n=91)$ and nutrition and health promotion $(n=9)$, with the majority identifying as female (91 versus 9 ). All students enrolled in the unit were provided information regarding the study methodology, rationale and timeline during the first unit lecture. Students were advised that participation was voluntary, anonymous and would not affect their mark or treatment in the unit. Of those invited to participate, informed consent was obtained from 40 students who undertook the diagnostic test. The study was approved by the Curtin University Ethics Committee (RDHS-2716) and complied with the Strengthening the Reporting of Observational Studies in Epidemiology (STROBE) statement for reports on cross-sectional studies (von Elm et al., 2014).

The online diagnostic test was available in week one of the semester. Students were provided verbal and written instructions on how to complete the test, along with an electronic link and password. The diagnostic test was administered using Qualtrics survey software. The test was designed within an interpretivism epistemology and constructionism ontology (Bryman, 2012). That is, as well as having students solve the questions (competence), the test investigated students' conviction of response (confidence) and how easy they found each question (perception of ease). In addition, students' anxiety, perceptions of attitudes and conceptualisation of mathematics were also measured (Cooke, 2015). Questions used in the diagnostic test were adapted from those used previously for education students and, where possible, framed in a biochemistry context.

Assessment of mathematical competence was based on answers to 21 multiple-choice questions designed to test student application of relevant mathematical skills, specifically: place value, fractions, percentage, number flexibility and equation manipulation. Each question had one correct answer and three distractors. Questions were tailored to the expected ability of students in the second year of their nutrition degree, as gauged by the content of the present unit and from prerequisite units. Participant confidence and perceptions of ease were measured using Likert-style questions, which followed each of the 21 competence questions. Students selected one of four options when asked, "How confident were you with your answer to ...?": "not confident at all", "slightly confident", "fairly confident" or "certain". Perception of ease was gauged by asking, "How hard did you find question ...?". Options given were: "extremely difficult", "somewhat difficult", "somewhat easy" and "extremely easy".

The second part of the test consisted of 21 Likert-style questions designed to comprehensively measure anxiety and attitudes towards mathematics and conceptualisation of mathematics, grouped into five disposition subscales (Table 1). Three mathematics anxiety domains were considered: (1) cognitive, (2) attitudinal and (3) mathematical knowledge/understanding (Cooke et al., 2011). The final 
mathematics anxiety domain, somatic, was not included, as this was not considered as part of the focus of this research. Questions on (4) attitudes towards mathematics were adapted from several items created by a research team lead by Beswick (K. Beswick, personal communication, December 22, 2013). The final items in the diagnostic tests related to (5) conceptualisation of mathematics (Cooke, 2015). The conceptualisation of mathematics scale discussed by Cooke (2015) was analysed using Rasch, but the results are presently unpublished. The five subscales were used to enable comparisons of the students' mean scores and the relationships between them and the students' competence. Further details of the design and validation of the diagnostic test and the types and style of questions used has been reported elsewhere (Beswick et al., 2011; Cooke et al., 2011).

\section{Table 1}

List of Items for Each of the Five Disposition Subscales Comprising Three Anxiety Domains, Attitudes Towards Mathematics and Conceptualisation of Mathematics

\begin{tabular}{|l|l|}
\hline Domain & \multicolumn{1}{|c|}{ Item } \\
\hline Cognitive anxiety & $\begin{array}{l}\text { When working with maths, I am aware of previous failures. } \\
\text { When working with maths, I am confused at the start or quickly become } \\
\text { confused. } \\
\text { I become easily frustrated when doing maths. } \\
\text { I do not feel I am in control of what I need to do with maths. } \\
\text { I feel uncomfortable working on maths. } \\
\text { I forget maths I normally know when I have to use it. }\end{array}$ \\
\hline Attitudinal anxiety & $\begin{array}{l}\text { I am not confident I can do what is required when working with maths. } \\
\text { I don't want to be doing maths. } \\
\text { I expect to have difficulty doing the maths that is required. } \\
\text { I feel threatened when I have to work on maths. }\end{array}$ \\
\hline $\begin{array}{l}\text { Mathematical knowledge/ } \\
\text { understanding anxiety }\end{array}$ & $\begin{array}{l}\text { I feel I'Il lack the maths knowledge to do what is required in my course. } \\
\text { I am scared I will make a mistake when working with maths. } \\
\text { I don't think I know enough about maths. }\end{array}$ \\
\hline Attitudes towards mathematics & $\begin{array}{l}\text { I often use the maths I learnt at school. } \\
\text { The maths I did at school has been very useful to me. } \\
\text { I see maths as useful in life. } \\
\text { I try to understand maths I have to use. } \\
\text { Using maths to find out about other things is enjoyable. } \\
\text { I view maths as something I can use to explain the world. }\end{array}$ \\
\hline Conceptualisation of mathematics & $\begin{array}{l}\text { It is important to know why mathematical rules and procedures work. } \\
\text { Maths is creative. }\end{array}$ \\
\hline
\end{tabular}


Data was exported from the Qualtrics platform, combined into a single spreadsheet and imported into SPSS version 24.0 (IBM ${ }^{\ominus}$ SPSS $^{\odot}$ Statistics, Armonk, NY). Each answer to the 21 questions addressing student mathematical competence was coded as $0=$ incorrect or $1=$ correct. A total mark was calculated, with the maximum possible mark 21, indicating all questions were answered correctly. The minimum possible mark $=0$, indicating no questions were answered correctly. Marks were also reported as percentage correct. Answers to Likert-type questions were converted to integers ranging from 1 to 4 , with 1 reflecting the most negative and 4 reflecting the most positive. The group mean value for all 21 questions are reported for confidence and perception of ease of questions. Scores for each of the five disposition subscales were also calculated as a mean. Data were tested for normality, linearity and homoscedasticity, and these assumptions were met. Relationships among numeric variables were determined as Pearson's product-moment correlation coefficients $(r)$. Statistical significance was accepted as a $p$ value of $<0.05$.

\section{Results}

The students who participated in the diagnostic test were mostly female (97.5\%), aged on average $23.1 \pm 6.7$ years, similar to the class as a whole $(91.3 \%$ female, average age $22.1 \pm 4.9$ years). All 40 students completed 21 mathematical understanding questions to assess competence, together with questions examining confidence and perception of ease. Students were competent, with an average score of $72 \%$ for the diagnostic test. Even though only four students scored below the midpoint for competence, with less than $50 \%$ of their answers correct, 14 were not confident with their answers, and 10 reported difficulty with questions, as defined by a rating below the midpoint for confidence and ease, respectively (Table 2).

\section{Table 2}

Descriptive Statistics for Mathematical Competence Scores, Confidence Ratings and Perceptions of Ease Ratings $(n=40)$

\begin{tabular}{l|c|c}
\hline Outcome & $\begin{array}{c}\text { Rating } \\
(\text { mean } \pm S D)\end{array}$ & $\begin{array}{c}\text { Students with ratings below } \\
\text { the midpoint }(n, \%)\end{array}$ \\
\hline Competence $^{\mathrm{a}}$ & $15.1 \pm 3.5$ & $4(10 \%)$ \\
\hline Confidence $^{\mathrm{b}}$ & $2.7 \pm 0.6$ & $14(35 \%)$ \\
\hline Perception of ease $^{\mathrm{b}}$ & $2.7 \pm 0.6$ & $10(25 \%)$ \\
\hline
\end{tabular}

Ratings represent the mean of all 21 diagnostic test questions.

${ }^{a}$ maximum possible score 21; midpoint 10.5

${ }^{b}$ maximum possible score 4; midpoint 2.5 
The associations between the competence rating, indicated by competence test score (\%) and student confidence and perception of ease ratings, and the association between student confidence and perceptions of ease were investigated (Figure 1). Students' mean confidence was found to positively correlate with their competence $(r(40)=0.691$, $p<0.001$ ), indicating that the more confident the student was in their answers, the higher the total mark achieved for the test. The line of equality (Figure 1, A) shows the relationship if confidence and competence were equally related. For instance, a student who was only half as confident as another student could be expected to obtain a $50 \%$ lower test mark. The majority (78\%) of students' data points lie above this line, indicating a lower confidence than expected from their competence rating. Furthermore, students' competence positively correlated with mean perception of the ease of the questions $(r(40)=0.707, p<0.001)$, further indicating that the easier the students found the question, the higher the total mark achieved. Similarly, the majority (85\%) of students' data points were above the line of equality (Figure 1, B), suggesting students found the questions more difficult than their actual understanding indicated. Association between mean confidence and perception of ease of the questions is shown in Figure 1, C. These measures demonstrated a strong positive correlation, indicating on average, students had greater confidence in their answers for questions they perceived to be less difficult $(r(40)=0.924, p<0.001)$. The number of student data points were evenly distributed above and below the line of equality (Figure 1, C), indicating students reported a similar magnitude of difficulty in relation to their lack of confidence with questions.

Scatterplots in Figure 1 were also partitioned into quadrants, allowing separate examination of students who were: competent, achieving at least a $50 \%$ pass mark; confident, above midpoint for mean confidence; and those who, on average, found the questions easy, above midpoint for mean perception of ease. It can be observed that by far, the majority of participants were located in quadrant II for graphs A and B, representing students who were both competent and either confident in their answers (A) or found questions relatively easy (B). However, there remained a number of students who, despite being competent, were not confident (A, quadrant I) or found the questions relatively difficult $(B$, quadrant $\mathrm{I}$ ). All four students who did not pass the diagnostic test had mean scores for reported ease of the question and mean scores for reported confidence with answers at less than midpoint for each scale (A and B, quadrant III). There were no students in quadrant IV for either graph A or B, indicating all students who had low mathematical competence were not confident with their answers and, also, found the questions difficult.

Higher disposition subscale values indicate a more positive disposition around mathematics. Greater values for anxiety indicate lower feelings of anxiety, and higher attitudes and conceptualisation ratings indicate a more positive attitude and capacity to conceptualise using mathematics. All mean values for the anxiety, attitudes and conceptualisation of mathematics subscales were above the midpoint of the respective scale (Table 3). The subscale with the lowest mean concerned the anxiety connected to mathematical knowledge and understanding. This subscale addressed anxiety about lack of knowledge or understanding of mathematics and making mistakes, both in general 


\section{Figure 1}

Associations Between Mathematical Competence, Confidence and Perception of Ease

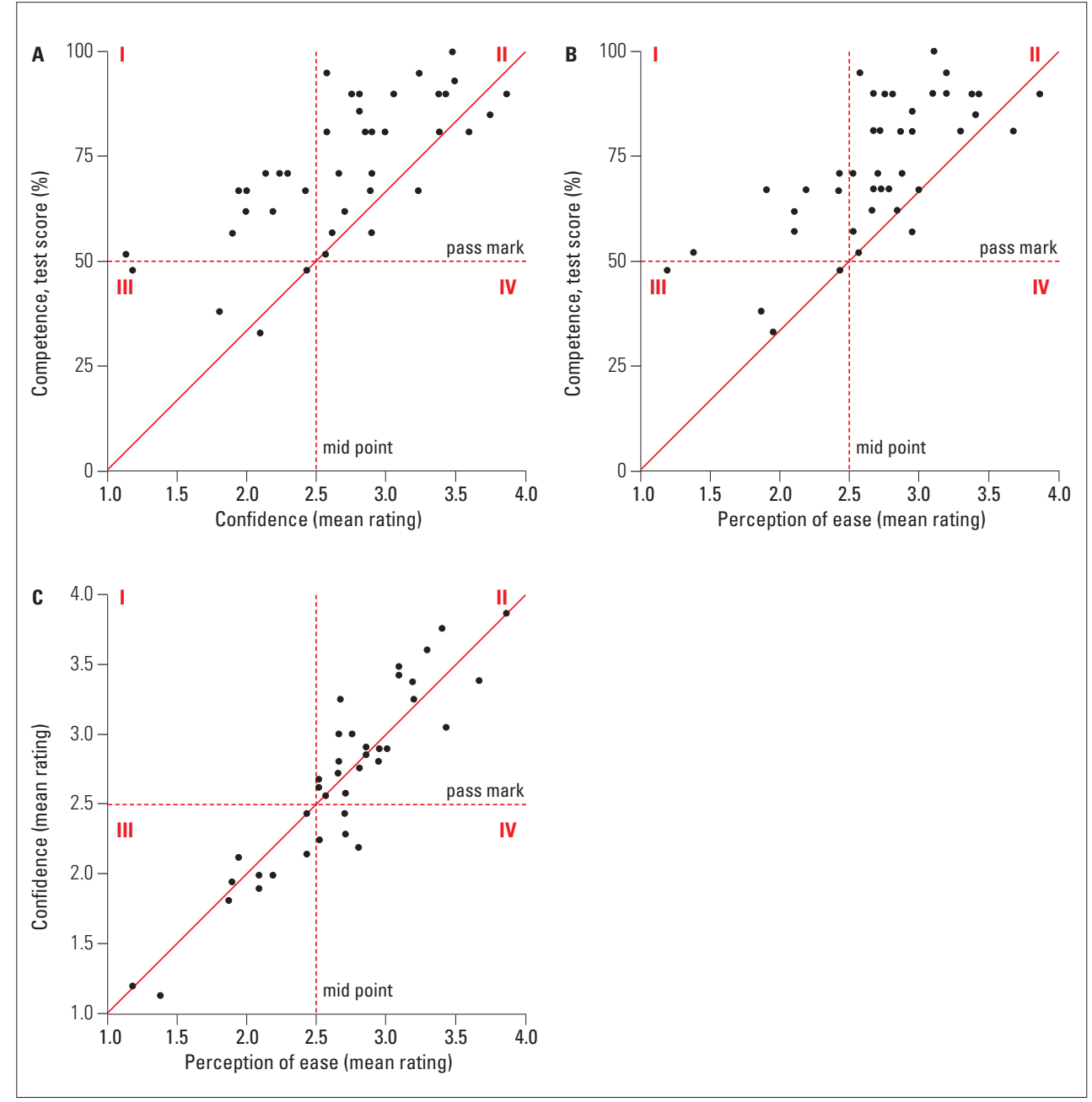

Note. Shown are associations between competence and confidence $(A)$ and perception of ease $(B)$ and between confidence and perception of ease (C). Quadrants are defined by the midpoint of axes (dashed red lines). Lines of equality are also shown (solid red lines).

and specific to the course of study. This anxiety subscale had the highest proportion of students below the midpoint, with $30 \%$ of students worried that they "lack the maths knowledge to do what is required", "scared [they] will make a mistake" or "don't ... know enough about maths". 


\section{Table 3}

Descriptive Statistics for Disposition Subscale Scores

\begin{tabular}{l|c|c}
\hline Outcome & $\begin{array}{c}\text { Rating } \\
\text { (mean } \pm \text { SD) }\end{array}$ & $\begin{array}{c}\text { Students with ratings below } \\
\text { the midpoint }(n, \%)\end{array}$ \\
\hline Cognitive anxiety & $3.0 \pm 0.7$ & $5(12.5 \%)$ \\
\hline Attitudinal anxiety & $3.0 \pm 0.8$ & $6(15 \%)$ \\
\hline $\begin{array}{l}\text { Mathematical knowledge/ } \\
\text { understanding anxiety }\end{array}$ & $2.7 \pm 0.9$ & $12(30 \%)$ \\
\hline Attitudes towards mathematics & $3.3 \pm 0.4$ & $1(2.5 \%)$ \\
\hline Conceptualisation of mathematics & $3.2 \pm 0.6$ & $4(10 \%)$ \\
\hline
\end{tabular}

Question ratings represent the mean of all 21 questions: maximum possible score 4, midpoint $2.5(n=40)$

\section{Discussion}

This research investigated the issue of numeracy in nutrition students by considering their mathematical ability to answer discipline-specific questions, their perceptions of ease of the questions and their confidence in the answers they gave. In addition, we explored the students' mathematical disposition and willingness to engage in mathematical thinking. Interestingly, although the majority of students (90\%) were competent, answering at least half of the test questions correctly, the indicated confidence in their answers tended to be lower than their competence would suggest. A similar disconnect was observed with their perception of the difficulty of the questions, i.e., that they were harder than their competence would suggest (Figure 1, A-B). Hence, although this group of students have an acceptable level of discipline-specific mathematical understanding, their numeracy may be limited by their perceptions of ease and their ability to confidently engage with mathematics. Anxiety around mathematics in general was also assessed, and in a similar vein, it was observed that nearly one third of these students reported anxiety concerned with mathematical understandings and knowledge (Table 3).

The strong and positive correlations observed between the students' ability to answer questions correctly with both their confidence and perceptions of ease is to be expected, as are those between the ratings of confidence and perception of ease (Figure 1, A-C). Of more interest, however, is that a substantial subset of students reported difficulty with confidence and perceptions of ease in the diagnostic test: $35 \%$ and $25 \%$ of students, respectively, and scored, on average, below the midpoint for these measures (Table 2, Figure 1, A-B). This is despite all students having successfully passed the prerequisite units allowing them to progress into the second year of the nutrition course. Interestingly, there were an additional 10 and 6 students, respectively, who, despite being competent in the numeracy diagnostic test, were not confident with their answers and/or found the questions difficult (Figure 1, A-B, quadrant I). These findings are similar to those reported by Quinnell and Wong (2007), who observed that despite a high level of numeracy competence, biology students reported a low confidence in 
their responses. Similarly, pre-service teachers reported low confidence despite high competency in numeracy (Cooke, 2014). These data indicate that students' perceptions of their mathematical skills may not match reality, and students tend to underestimate their ability. Thus, students' perceptions may have greater impact on their numeracy than their competence, with perceptions (ease and confidence) only accounting for close to half of the variance in competence, whereas over $80 \%$ of the variance is shared between confidence and perception of ease.

As shown in Figure 1, A-B, the four students who had a competency score below 50\% were all located in quadrant III, indicating, on average, they were also not confident with their answers and found them difficult. This indicates a minority of students may require an intervention that addresses both their mathematical ability and disposition in order to successfully remain in the nutrition course. Such students could benefit from extracurricular mathematics support services. There were no students who failed the diagnostic test despite being confident in their mathematical ability or thinking the questions were easy (Figure 1, A-B, quadrant IV). This result is not surprising in a predominantly female student cohort. Compared with males, females are more likely to have lower confidence around numeracy and science (Mallow, 2006).

Although the majority of these students exhibited satisfactory competence for this level of their course, their willingness to engage with mathematical problems may be affected by past experiences and their disposition towards mathematics (Lisciandro et al., 2018). When asked about their disposition, 12 of the 40 students had anxiety concerned with mathematical understanding and knowledge (Table 3). This data indicates that nearly one third of the students worried that they "lack the maths knowledge to do what is required", are "scared [they] will make a mistake" and "don't ... know enough about math". Teaching and learning literature indicate that ability is just one of several aspects to numeracy (AAMT \& Education Department of Western Australia, 1997; Boreland, 2016; Galligan, 2011, 2013; Galligan \& Hobohm, 2015). Individuals may have the ability to answer questions correctly but struggle with confidence, critical awareness and willingness to participate. These features were evident, with respondents worried about their mathematical knowledge and understanding. Throughout the nutrition degree, students need to be able to identify mathematical ideas and apply them in a professional context. A willingness to participate in activities involving numeracy increases the chance of understanding and succeeding in all aspects of their discipline. It could be argued that having confidence and critical awareness would be more crucial in the workforce when students graduate and are not under the instruction of a tutor. If students lack the confidence and willingness to engage in mathematics because of increased anxiety, a key role of learning support may be to address disposition and negative attitudes. Fundamentally, a positive disposition around mathematics increases the likelihood of student and graduate willingness to "have a go" (AAMT \& Education Department of Western Australia, 1997) and pursue mathematical challenges.

Gendered perceptions of mathematics ability is a worldwide phenomenon (Forgasz et al., 2014). The erroneous belief that mathematical ability is a natural "talent" (Mallow, 2006, p. 4) that cannot be developed may explain why more females choose careers that favour 
maths and science avoidance. The majority of participants in this study (97.5\%), and those enrolled in the nutrition course at Curtin University (90\%), are female. Australia wide, over $70 \%$ of students studying a health-related course (including nutrition) are female (Australian Government Department of Education and Training, 2018). When choosing nutrition as their course of study, students may not have appreciated the relevance of mathematics. This discordance between expectation and reality could be detrimental to their confidence (Lisciandro et al., 2018), satisfaction and motivation to engage with their course. Moreover, teaching staff who are not confident in presenting mathematical concepts may transfer their own anxiety to students through nonverbal behaviours. Conversely, teacher enthusiasm can transmit positive emotions to students. Our results show a subset of competent students were not optimistic (Figure 1, A-B, quadrant I). Thus, a worthy focus to enhance mathematical capabilities of nutrition students may be on building characteristics of optimism, together with resilience and persistence in students who are competent, to create confident successful learners (Boaler, 2013; Clarke et al., 2014; Dweck, 2006; Williams, 2014).

Participation in this study was voluntary, anonymous and offered to all students enrolled in the unit. The relatively high participation rate of 40 percent represents a major strength of this study and itself may be an indication that students wish to address the uncomfortable issue of numeracy. The issue of gender discrepancy in optimism and confidence around numeracy should be further explored, as all but one of the study participants were female. Why the majority of males chose not to participate could be a gendered reflection of confidence in mathematical ability. Conceivably, the majority of males did not identify numeracy as an issue in need of addressing as the females did. We suggest that findings from our study may be applicable to the wider nutrition student cohort, as the majority of nutrition students in Australia are female.

\section{Conclusion}

The main findings from this research are that undergraduate nutrition students exhibit anxiety around mathematical knowledge and understanding, which translated into ratings of confidence and perception of ease that were not commensurate with their competence. Given what we know about numeracy in this cohort of predominantly female undergraduate nutrition students, the next stage of this research would be to tailor specific learning support to help students develop the capacity to think mathematically. Aspects of how mathematics is taught in the nutrition curriculum could be adapted from other disciplines, including the School of Education, Curtin University (Cooke, 2014) and that published in other health sciences disciplines (McNaught \& Hoyne, 2013). In order to promote students' willingness to engage with mathematics and address knowledge anxieties, it is critical to ensure that intervention material is contextualised and relevant for nutrition. Teaching examples should be authentic (Lisciandro et al., 2018) so that students appreciate mathematics as a tool to help them solve meaningful problems in nutrition. Adequate training of teaching staff should focus on delivery and feedback and, in doing so, should address feelings, beliefs and values around mathematical content. Success of an intervention could be measured 
as an increase in the proportion of students who report being optimistic in their use of mathematics during their course and who can confidently take these attributes into the nutrition workforce.

\section{Funding and conflict of interest statement}

This research was supported by a Curtin University Teaching Excellence Development Fund. The authors have no conflicts of interest to declare.

\section{References}

Arkell, S., \& Rutter, P. M. (2012). Numeracy skills of undergraduate entry level nurse, midwife and pharmacy students. Nurse Education in Practice, 12(4), 198203. https://doi.org/10.1016/j.nepr.2012.01.004

Australian Association of Mathematics Teachers (AAMT), \& Australian Industry Group (AI Group). (2014). Identifying and supporting quantitative skills of 21st century workers: Final report. Author.

Australian Association of Mathematics Teachers (AAMT), \& Education Department of Western Australia. (1997). Numeracy = everyone's business: The report of the Numeracy Education Strategy Development Conference. Author.

Australian Government Department of Education, Skills and Employment. (2018). uCube: Award Courses Completions Time Series, Field of Education. http:// highereducationstatistics.education.gov.au/

Beswick, K., Ashman, D., Callingham, R., \& McBain, D. (2011, November 27 December 1). Teachers' and preservice teachers' confidence to teach primary school mathematics. Paper presented at the 2011 Australian Association for Research in Education Conference, Hobart, TAS, Australia. https:/www.aare.edu.au/data/ publications/2011/aarefinal00535.pdf

Boaler, J. (2013). Ability and mathematics: The mindset revolution that is reshaping education. Forum, 55(1), 143-152.

Boreland, J. (2016). Failing quantitative literacy: But who is failing? Students or universities? Journal of Academic Language and Learning, 10(1), A57-A68.

Brady, K. (2014, July 6). Developing first-year students' academic numeracy skills: Toward a whole-of-institution approach. Paper presented at the 2014 International First Year in Higher Education Conference, Darwin, NT, Australia. http://fyhe.com.au/ past_papers/papers14/06D.pdf

Bryman, A. (2012). Social research methods (4th ed.). Oxford University Press.

Clarke, D., Roche, A., Cheeseman, J., \& Sullivan, P. (2014). Encouraging students to persist when working on challenging tasks: Some insights from teachers. Australian Mathematics Teacher, 70(1), 3-11.

Cooke, A. (2014, 29 June). Preliminary investigations of pre-service teacher numeracy. Paper presented at the 37th annual conference of the Mathematics Education Research Group of Australasia, Sydney, Australia. 
Cooke, A. (2015). Considering pre-service teacher disposition towards mathematics. Mathematics Teacher Education and Development, 17(1), 1-11.

Cooke, A., Cavanagh, R., Hurst, C., \& Sparrow, L. (2011, November 27 December 1). Situational effects of mathematics anxiety in pre service teacher education. Presented at the 2011 Australian Association for Research in Education Conference, Hobart, TAS, Australia. https:/www.aare.edu.au/data/ publications/2011/aarefinal00501.pdf

Dietitians Association of Australia (DAA). (2015). National competency standards for dietitians in Australia. https://Daa.Asn.Au/Wp-Content/Uploads/2017/01/NCSDietitians-Australia-1.0.Pdf

Donaldson, J. H., McCallum, J., \& Lafferty, P. (2010). Can we predict successful completion of the common foundation programme at interview? Nurse Education Today, 30(7), 649-656. https://doi.org/10.1016/j.nedt.2009.12.019

Dweck, C. (2006). Disposition: The new psychology of success. Ballantine.

Forgasz, H., Leder, G., \& Tan, H. (2014). Public views on the gendering of mathematics and related careers: International comparisons. Educational Studies in Mathematics, 87(3), 369-388. https://doi.org/10.1007/s10649-014-9550-6

Galligan, L. (2011, July 3-7). Measuring academic numeracy: Beyond competence testing. Paper presented at the Mathematics Education Research Group of Australasia and the Australian Association of Mathematics Teachers Conference, Alice Springs, NT, Australia. https://www.merga.net.au/Public/Public/ Publications/Annual_Conference_Proceedings/2011_MERGA_CP.aspx

Galligan, L. (2013). Becoming competent, confident and critically aware: Tracing academic numeracy development in nursing. Adults Learning Mathematics, 8(1), 20-30.

Galligan, L., \& Hobohm, C. (2015). Investigating students' academic numeracy in 1 st level university courses. Mathematics Education Research Journal, 27(2), 129145 .

Isiksal, M., Curran, J. M., Koc, Y., \& Askun, C. S. (2009). Mathematics anxiety and mathematical self-concept: Considerations in preparing elementary-school teachers. Social Behavior and Personality, 37(5), 631-643. https://doi.org/10.2224/ sbp.2009.37.5.631

James, A. P. (2015). Unpublished observations. Curtin University.

Johnson, P., \& O'Keeffe, L. (2016). The effect of a pre-university mathematics bridging course on adult learners' self-efficacy and retention rates in STEM subjects. Irish Educational Studies, 35(3), 233-248. https://doi.org/10.1080/03323 315.2016.1192481

Kemp, M., \& Hogan, J. (2000). Planning for an emphasis on numeracy in the curriculum. Department of Education, Training and Youth Affairs, Australian Government. http://www.aamt.edu.au/content/download/1251/25266/file/kemphog.pdf 
Lawlis, T., Torres, S. J., Coates, A. M., Clark, K., Charlton, K. E., Sinclair, A. J., Wood, L. G., \& Devine, A. (2019). Development of nutrition science competencies for undergraduate degrees in Australia. Asia Pacific Journal of Clinical Nutrition, 28(1), 166-176. https://doi.org/10.6133/apjcn.201903_28(1).0022

Lisciandro, J. G., Jones, A., \& Geerlings, P. (2018). Enabling learners starts with knowing them: Student attitudes, aspiration and anxiety towards science and maths learning in an Australian pre-university enabling program. Australian Journal of Adult Learning, 58(1), 13-40.

Mallow, J. V. (2006). Science anxiety: Research and action. In J. Mintzes \& W. Leonard (Eds.), Handbook of college science teaching (pp. 3-14). National Science Teachers Association.

McNaught, K., \& Hoyne, G. (2013). Testing program reveals deficient mathematics for health science students commencing university. Issues in Educational Research, 23(2), 180-195. http://www.iier.org.au/iier23/mcnaught.pdf

Nutrition Society of Australia (NSA). (n.d.) Competencies in nutrition science. https:// nsa.asn.au/wp-content/uploads/2019/10/competencies-in-nutrition-science.pdf

Quinnell, R., \& Wong, E. (2007). Using intervention strategies to engage tertiary biology students in their development of numeric skills. Paper presented at the Australian Conference on Science and Mathematics Education (formerly Uniserve Science Conference), Sydney, Australia. http://openjournals.library.usyd.edu.au/index. php/IISME/article/view/6347

von Elm, E., Altman, D. G., Egger, M., Pocock, S. J., Gotzsche, P. C., Vandenbroucke, J. P., \& Initiative, S. (2014). The Strengthening the Reporting of Observational Studies in Epidemiology (STROBE) Statement: Guidelines for reporting observational studies. International Journal of Surgery, 12(12), 14951499. https://doi.org/10.1016/j.ijsu.2014.07.013

Wilkins, L. (2016). The role and positioning of numeracy in Australian universities: Does it matter? Journal of Academic Language and Learning, 10(1), A69-A86.

Williams, G. (2014). Optimistic problem-solving activity: Enacting confidence, persistence, and perseverance. $Z D M, 46(3), 407-422$. https://doi.org/10.1007/ s11858-014-0586-y 